\title{
The Gay Men Sex Studies: prevalence of sexual dysfunctions in Belgian $\mathrm{HIV}^{+}$gay men
}

This article was published in the following Dove Press journal:

HIVIAIDS - Research and Palliative Care

25 April 2013

Number of times this article has been viewed

\author{
Johan Vansintejan \\ Joris Janssen \\ Erwin Van De Vijver \\ Jan Vandevoorde \\ Dirk Devroey
}

Department of Family Medicine, Vrije Universiteit Brussel (VUB),

Brussels, Belgium
Correspondence: Johan Vansintejan Department of Family Medicine,

Vrije Universiteit Brussel (VUB)

I03 Laarbeeklaan, Brussels

B-1090, Belgium

Tel +32 247743 I I

Fax +32 24774301

Email johan.vansintejan@vub.ac.be

\begin{abstract}
The aim of this Internet-based survey was to investigate the prevalence and associated predictors of sexual dysfunctions in Belgian self-reported HIV-positive men who have sex with other men. Of the 72 participants, $56 \%$ had a mild-to-severe erectile dysfunction, and $15 \%$ reported a hypoactive sexual desire disorder. The prevalence of premature ejaculation and anodyspareunia was $18 \%$ for both. Independent predictors for erectile dysfunction were frequency of masturbation, frequency of sex with partner, use of erectile enhancement drugs, having a passive sex role, and not having a steady relationship. Independent predictors for hypoactive sexual desire disorder were frequency of masturbation and having a lower lifetime number of sexual partners. Independent predictors for premature ejaculation were not having a steady relationship, having a lower lifetime number of sexual partners, and a lower level of education. The only independent predictor for anodyspareunia was having an active sex role.
\end{abstract}

Keywords: homosexuality/male, sexual dysfunction, HIV, epidemiology

\section{Introduction}

Three decades into the AIDS era, the prevalence of HIV is still rising in Belgium. ${ }^{1}$ HIV has become endemic in the group of men who have sex with men (MSM), and prevention efforts seem to be failing to reduce HIV incidence in this population. ${ }^{2}$ In 2010, a total of 1196 new cases were recorded in Belgium, of which 376 had Belgian nationality. ${ }^{3}$ Homosexual contact was the way of transmission in $81 \%$ of the Belgian male population. The prevalence of sexual dysfunction (SD) in HIV-infected $\left(\mathrm{HIV}^{+}\right)$ MSM was previously investigated in different cohort groups, ranging from $43 \%$ up to $79 \%{ }^{4-12}$ Different study designs, diagnostic tools, and study periods can explain this large range. With the recently available combination therapy, the quality of life and the life expectancy of persons living with HIV are improving further. ${ }^{13,14}$ As age is an important predictor of SD, thorough insight in these topics is required. ${ }^{4,15}$ Homosexuality as well as being $\mathrm{HIV}^{+}$are independent risk factors for having an $\mathrm{SD} .{ }^{16}$ Since the introduction of highly active antiretroviral therapy, the proportion of $\mathrm{HIV}^{+} \mathrm{MSM}$ with SD has increased..$^{10}$ Platteau and van Lankveld suggested several explanations: a reintroduced and higher level of sexual activity in this group, a lower threshold for discussing sexual problems, a psychological inhibition towards sexual activity as HIV is a sexually transmitted disease (STD), and the possible influence of medication. ${ }^{16}$

To our knowledge, no research on SD in the Belgian $\mathrm{HIV}^{+}$MSM population has been published yet. In 1999, one study examined the prevalence of erectile dysfunction (ED) in the general male population in Belgium. Regardless of sexual preference, it showed a prevalence of $61 \% .{ }^{17}$ Less is known about the prevalence of pain during or 
after having anal intercourse, also known as anodyspareunia (AD). One study found 14\% prevalence in 404 MSM, with no significant difference between $\mathrm{HIV}^{+}$and $\mathrm{HIV}^{-}$persons. ${ }^{18}$ The prevalence of hypoactive sexual desire disorder (HSDD) in the general male population is estimated to be $15 \%$, in contrast to $30 \%$ in the female population. ${ }^{19}$ Premature ejaculation $(\mathrm{PE})$ has had more attention from researchers, and some studies show that it is more present in $\mathrm{HIV}^{+}$ $\mathrm{MSM}^{20}$ The prevalence of PE in the general (heterosexual and homosexual) male population is estimated to be around $30 \%$, varying from $25 \%$ to $60 \%$ depending on the diagnostic tools used. ${ }^{19}$ However, a very recent study by McMahon et al of 4997 men showed a prevalence of only $16 \% .^{21}$

The present study aims to investigate the prevalence of $\mathrm{SD}$ in the Belgian $\mathrm{HIV}^{+} \mathrm{MSM}$ population, as well as associations between patient characteristics and different subtypes of SD.

\section{Methods}

\section{Participants}

We used the data of the online Gay Men Sex Studies (GAMESSS). ${ }^{22}$ The subjects were recruited by the distribution of 25,000 flyers during various gay events across Belgium. Hyperlinks to the questionnaire were placed on multiple, mostly gay-orientated, Belgian websites. The registration period ran from April 2008 to December 2008. Participation in this study was completely anonymous and voluntary. The study population comprised Belgian MSM aged 18 years or older. Their sexual orientation was identified by using Kinsey's Heterosexual-Homosexual Rating Scale. ${ }^{23}$ This paper discusses the results of the $\mathrm{HIV}^{+}$subpopulation. HIV status was retrieved by a self-report question.

\section{Questionnaire}

The GAMESSS questionnaire was available in Dutch, French, and English. Several validated diagnostic tools were combined into one questionnaire consisting of 90 questions. The Index of Premature Ejaculation (IPE) was used to detect ejaculation problems. ${ }^{24}$ This ten-item validated instrument had a Cronbach's alpha of 0.7. For the evaluation of ED, an abbreviated version of the International Index of Erectile Function (IIEF) was used, namely the IIEF-5. ${ }^{25}$ These five questions, consisting of a 5-point Likert scale, had a Cronbach's alpha of 0.91 . For evaluating pain during or after anal intercourse, no validated tests were available. We created an adapted version of the pain domain of the Female Sexual Function Index (FSFI), in which we substituted the word "vaginal" with "anal."26,27 These three questions each had six Likert-type items. No validated test was available for evaluating HSDD in men. We overcame this shortcoming by using the desire domain of the FSFI. This 6-point Likertscale questionnaire consisting of six questions is not genderspecific. The internal consistency of the SD domain of the FSFI was found to have a Cronbach's alpha of 0.92 .

When available, a validated cutoff point was used to determine the absence or presence of an SD. An IIEF-5 score of less than 22 was used for the determination of ED. An FSFI desire domain score of less than 6 was used as the cutoff point for the presence of HSDD. To our knowledge, there have not been any validated cutoff points developed for the IPE or the pain-domain score of the FSFI. To estimate the prevalence of $\mathrm{PE}$ and $\mathrm{AD}$, we used cutoff points at $50 \%$ and $66 \%$ of the total score, with a score of $50 \%$ corresponding with answers like "about half of the time" or "moderate level of discomfort," and a score of $66 \%$ corresponding with answers such as "high confidence' or "most times." We adopted this idea from the study of Ferguson et al, who encountered the same problem. ${ }^{28}$ The choice of these definitions was not based on any statistical evidence, but it gave us a general sense of the prevalence and the influence of other variables on these SDs.

$\mathrm{SD}$ is a term covering a wide range of physiologic or psychological disturbances in normal sexual performance, affecting quality of life. This paper focused on four different SDs. First, ED: “defined as the consistent or recurrent inability of a man to attain and/or maintain penile erection sufficient for sexual activity." 29 Second, AD: persisting or recurrent pain with attempted or complete anal entry. ${ }^{18}$ Third, HSDD: persistently or recurrently deficient (or absent) sexual fantasies and desire for sexual activity in men. ${ }^{30}$ And last, PE: a combination of short ejaculatory latency, lack of control over ejaculation, and lack of sexual satisfaction. ${ }^{31}$

\section{Statistical analysis}

The following parameters were tested for their correlation with each specific SD: age, lifetime number of sexual partners, level of education, use of poppers (a slang term for various alkyl nitrites which are inhaled as an aphrodisiac), use of erectile enhancement products (EEPs), having a steady relationship, number of sex partners at the same time, frequency of masturbation, frequency of sex with partner, and sex role. First, we performed a bivariate regression analysis for every parameter, with every specific SD as the dependent variable. Secondly, every parameter that had a $P$-value $<0.15$ was put in a multivariate stepwise logistic regression. Statistical significance was set at $P<0.05$. Data were analyzed 
using bivariate and multivariate logistic regression analyses (backward Wald). SPSS version 19 (IBM, Armonk, NY, USA) was used for all analysis.

\section{Results \\ Participants}

In total, 4006 persons started to answer the questionnaire. With a dropout of $39 \%, 2438$ participants fully completed the questionnaire. The questionnaires that were not fully completed were excluded from the analyses. Of the $78 \mathrm{HIV}^{+}$ MSM that completed the questionnaire, 72 had been sexually active at least once in the 4 weeks prior to the study. Sexual activity was defined as having any form of sexual activity with a partner of the same sex, like mutual masturbation, oral sex, and/or anal sex. The other six participants were excluded because they had not had sex with a partner in the last 4 weeks. The presented results are based only on these 72 subjects. Their characteristics are summarized in Table 1.

The participants had a mean age of 41 years (standard deviation 10 years, range $18-88$ years). A steady sexual relationship was reported by $58 \%$ of the cohort, but a part of the cohort had also had sex with other men besides their boyfriend/husband. A total of $67 \%$ reported having had more than 100 different sexual partners in their life, with $28 \%$ of the total cohort having had more than ten sexual partners at the same time. With these results, we can say that MSM have more promiscuous sexual behavior.

Forty-two percent of our population masturbated daily, and $88 \%$ at least once a week. Poppers were used by $69 \%$. The use of EEPs was reported by $33 \%$. Sildenafil was used by $20 \%$ of the participants, and tadalafil and vardenafil were each used by $4 \%$ of the responders. A remarkable proportion of nearly $72 \%$ were using Kamagra, a brand of sildenafil citrate, illegal in Belgium.

The sample was limited to 72 participants. To estimate the presence of an $\mathrm{SD}$, we calculated the number of responders who scored $50 \%$ or less of the total possible score and the number of responders who scored $66 \%$ or less of the total score. When using the most severe cutoff points for PE and $\mathrm{AD}$ ( $66 \%$ of the total score), $61 \%$ of the participants had an SD. When using less severe cutoff points (50\% of the total score), $68 \%$ of the participants had an SD.

\section{Erectile dysfunction}

Forty of the 72 participants had an IIEF-5 score less than 22. This means that $56 \%$ of our participants had at least a mild form of ED. After multivariate analysis, a significant correlation was seen between ED and frequency of masturbation,
Table I Characteristics of the study population $(n=72)$

\begin{tabular}{|c|c|}
\hline \multicolumn{2}{|l|}{$\overline{\text { Age }}$} \\
\hline$<30$ years & $18.1 \%$ \\
\hline $30-39$ years & $30.6 \%$ \\
\hline $40-49$ years & $33.3 \%$ \\
\hline$>50$ years & $18.1 \%$ \\
\hline \multicolumn{2}{|c|}{ Highest level of education } \\
\hline Primary school & $2.8 \%$ \\
\hline Secondary school & $43.0 \%$ \\
\hline Higher education & $38.9 \%$ \\
\hline University & $23.5 \%$ \\
\hline \multicolumn{2}{|c|}{ Lifetime number of sexual partners } \\
\hline II to 50 & $15.3 \%$ \\
\hline $51-100$ & $18.1 \%$ \\
\hline $10 \mid-500$ & $30.6 \%$ \\
\hline$>500$ & $36.1 \%$ \\
\hline \multicolumn{2}{|c|}{ Number of sexual partners at the same time } \\
\hline 2 & $11.1 \%$ \\
\hline 3 & $5.6 \%$ \\
\hline 4 or 5 & $37.5 \%$ \\
\hline 6 to 10 & $18.1 \%$ \\
\hline$>10$ & $27.8 \%$ \\
\hline \multicolumn{2}{|l|}{ Steady relationship } \\
\hline Yes & $58.3 \%$ \\
\hline No & $41.7 \%$ \\
\hline \multicolumn{2}{|c|}{ Frequency of masturbation } \\
\hline$>$ I time per day & $11.1 \%$ \\
\hline Daily & $30.6 \%$ \\
\hline I-3 times per week & $45.8 \%$ \\
\hline $1-3$ times per month & $8.3 \%$ \\
\hline$<\mathrm{I}$ time per month & $4.2 \%$ \\
\hline \multicolumn{2}{|c|}{ Frequency of sex with a partner } \\
\hline Daily & $5.6 \%$ \\
\hline$>2$ times per week & $19.4 \%$ \\
\hline I-2 times per week & $47.2 \%$ \\
\hline $1-3$ times per month & $20.8 \%$ \\
\hline$<\mathrm{I}$ time per month & $6.9 \%$ \\
\hline \multicolumn{2}{|l|}{ Sex role } \\
\hline Exclusive active & $2.8 \%$ \\
\hline Versatile & $91.7 \%$ \\
\hline Exclusive passive & $5.6 \%$ \\
\hline \multicolumn{2}{|c|}{ Use of erectile enhancement products } \\
\hline Yes & $33.3 \%$ \\
\hline No & $66.7 \%$ \\
\hline \multicolumn{2}{|l|}{ Use of poppers } \\
\hline Yes & $69.4 \%$ \\
\hline No & $30.6 \%$ \\
\hline
\end{tabular}

frequency of sex with partner, use of EEPs, having a more passive sex role, and not having a steady relationship (Table 2).

\section{Anodyspareunia}

Five participants that had had no anal sex in the last 4 weeks were excluded for the analyses on $\mathrm{AD}$. The prevalence of $\mathrm{AD}$ in the remaining 67 participants was $3 \%$ and $18 \%$, using as cutoff points, respectively, an FSFI pain score less than 
Table 2 Logistic regression for ED in a group of 72 Belgian $\mathrm{HIV}^{+}$MSM

\begin{tabular}{|c|c|c|c|c|c|c|}
\hline & \multicolumn{3}{|c|}{ Bivariate analysis $(95 \% \mathrm{Cl})$} & \multicolumn{3}{|c|}{ Multivariate analysis* $(95 \% \mathrm{Cl})$} \\
\hline & Odds ratio & $95 \% \mathrm{Cl}$ & $\mathbf{P}$ & Odds ratio & $95 \% \mathrm{Cl}$ & $\mathbf{P}$ \\
\hline \multicolumn{7}{|c|}{ Comparison of subjects with or without ED (IIEF-5 < 22) } \\
\hline Age (years) & 1.04 & $1.00-1.04$ & 0.07 & & & \\
\hline Frequency of masturbation & 2.36 & $1.28-4.36$ & 0.01 & 3.2 & I.39-7.37 & 0.01 \\
\hline Frequency of sex with partner & 1.88 & $1.08-3.27$ & 0.03 & 2.44 & $1.09-5.47$ & 0.03 \\
\hline No steady relationship & 2.83 & $1.05-7.6$ & 0.04 & 5.95 & $1.41-25.19$ & 0.02 \\
\hline More passive sex role & 2 & $1.08-3.7$ & 0.03 & 2.74 & $1.18-6.39$ & 0.02 \\
\hline Use of erectile enhancement drugs & 4.89 & $1.57-15.25$ & 0.01 & 12.87 & $2.54-65.37$ & $<0.001$ \\
\hline Use of poppers & 3.11 & I.10-8.83 & 0.03 & & & \\
\hline
\end{tabular}

Note: *In the multivariate analysis, both forward and backward stepwise logistic regression analysis was performed, with identical results.

Abbreviations: ED, erectile dysfunction; MSM, men who have sex with men; IIEF-5, International Index of Erectile Function 5; CI, confidence interval.

$50 \%$ or $66 \%$. After multivariate regression, a significant correlation was seen between $\mathrm{AD}$ and having a more active sex role (Table 3).

\section{Hypoactive sexual desire disorder}

In our study, $15 \%$ of the participants reported an HSDD. After multivariate analysis, a significant association was seen between HSDD and frequency of masturbation and having a lower lifetime number of sexual partners (Table 4).

\section{Premature ejaculation}

The prevalence of PE was 4\% and 18\% for IPE scores less than $50 \%$ or $66 \%$ of the total score, respectively. With the cutoff point at $50 \%$, no significant correlations were found after bivariate logistic regression. With the cutoff point set at $66 \%$, a significant correlation was seen, after multivariate regression, between $\mathrm{PE}$ and not having a steady relationship, having a lower lifetime number of sexual partners, and a lower level of education (Table 5).

\section{Discussion}

To our knowledge, this was the first study conducted in Belgium that focused on SD in $\mathrm{HIV}^{+} \mathrm{MSM}$. Although the study population was relatively small, it may give us an overview of some aspects of the sexual health in this population. The study group was not collected through an HIV center but through an Internet survey, which can explain the low number of $\mathrm{HIV}^{+}$participants. The survey was not presented solely to specific $\mathrm{HIV}^{+}$MSM groups in Belgium.

\section{Erectile dysfunction}

The most prevalent SD was ED, with $56 \%$. This is more than the $45 \%$ found in the non-HIV ${ }^{+}$cohort of our survey, and far more than the $21 \%$ in $\mathrm{HIV}^{+} \mathrm{MSM}_{\text {recently reported }}$ by Hart et al (ED defined as IIEF-MSM-EF < 17). ${ }^{32}$ Our results are remarkably lower than the $74 \%$ prevalence (ED defined as an IIEF-5 < 22) reported by Ende et al in a population of $118 \mathrm{HIV}^{+} \mathrm{MSM}^{33} \mathrm{We}$ found in the non-HIV ${ }^{+}$study group significant associations between ED and age, having a steady relationship, frequency of sex with their partner, and a more passive sex role. This corresponds partly with the findings of the present study. Another recent, Internet-based survey done by Shindel et al focused on ED and PE in MSM. ${ }^{20}$ This study covered $\mathrm{HIV}^{+}$as well as non-HIV ${ }^{+} \mathrm{MSM}$, also showing a significant association between seropositivity and ED. As in our study, they found significant associations between ED (defined by an IIEF-MSM-EF score $\leq 15$ ) and not being in a steady

Table 3 Logistic regression for AD in a group of 72 Belgian HIV+ MSM

\begin{tabular}{|c|c|c|c|c|c|c|}
\hline & \multicolumn{3}{|c|}{ Bivariate analysis $(95 \% \mathrm{Cl})$} & \multicolumn{3}{|c|}{ Multivariate analysis* $(95 \% \mathrm{Cl})$} \\
\hline & Odds ratio & $95 \% \mathrm{Cl}$ & $P$ & Odds ratio & $95 \% \mathrm{Cl}$ & $P$ \\
\hline \multicolumn{7}{|c|}{ Comparison of subjects with or without AD $(F S F I$ pain $\leq 10)$} \\
\hline Higher level of education & 0.58 & $0.4 \mathrm{I}-\mathrm{I} .12$ & 0.13 & & & \\
\hline Sum of lifetime sex partners & 0.63 & $0.35-1.12$ & 0.12 & & & \\
\hline Frequency of sex with partner & 1.86 & $0.93-3.27$ & 0.08 & & & \\
\hline More passive sex role & 0.42 & $0.20-0.91$ & 0.03 & 0.4 & $0.18-0.87$ & 0.02 \\
\hline \multicolumn{7}{|c|}{ Comparison of subjects with or without AD (FSFI pain $\leq 7)$} \\
\hline More passive sex role & 0.07 & $0.01-0.78$ & 0.03 & 0.07 & $0.01-0.78$ & 0.03 \\
\hline
\end{tabular}

Note: *In the multivariate analysis, both forward and backward stepwise logistic regression analysis was performed, with identical results.

Abbreviations: AD, anodyspareunia; MSM, men who have sex with men; FSFI, Female Sexual Function Index; Cl, confidence interval. 
Table 4 Logistic regression for HSDD in a group of 72 Belgian HIV+ MSM

\begin{tabular}{|c|c|c|c|c|c|c|}
\hline & \multicolumn{3}{|c|}{ Bivariate analysis $(95 \% \mathrm{Cl})$} & \multicolumn{3}{|c|}{ Multivariate analysis* $(95 \% \mathrm{Cl})$} \\
\hline & Odds ratio & $95 \% \mathrm{Cl}$ & $\mathbf{P}$ & Odds ratio & $95 \% \mathrm{Cl}$ & $\boldsymbol{P}$ \\
\hline \multicolumn{7}{|c|}{ Comparison of subjects with or without HSDD (FSFI desire $<6$ ) } \\
\hline Sum of lifetime sex partners & 0.55 & $0.30-1.00$ & 0.05 & 0.46 & $0.24-0.89$ & 0.02 \\
\hline Frequency of masturbation & 2.11 & $1.02-4.35$ & 0.04 & 2.44 & $1.07-5.60$ & 0.04 \\
\hline More passive sex role & 2.14 & $05 / 14 / 89$ & 0.09 & & & \\
\hline Frequency of sex with partner & 1.75 & $0.86-3.56$ & 0.12 & & & \\
\hline No steady relationship & 2.89 & $0.76-10.97$ & 0.12 & & & \\
\hline
\end{tabular}

Note: *In the multivariate analysis, both forward and backward stepwise logistic regression analysis was performed, with identical results.

Abbreviations: HSDD, hypoactive sexual desire disorder; MSM, men who have sex with men; FSFI, Female Sexual Function Index; Cl, confidence interval.

relationship, use of EEPs, and having a more exclusively passive sex role. ${ }^{20}$

Shindel et al did a separate multivariate analysis for PE (defined by Premature Ejaculation Diagnostic Tool [PEDT] score $\geq 9$ ), which confirmed our findings that a lower lifetime number of sexual partners is associated with PE. ${ }^{20}$ They found significant associations between ED as well as PE and age that could not be confirmed in our research. Frequency of masturbation, level of education, and frequency of sex with partner was not included in their survey. A comprehensive review on the prevalence of $\mathrm{PE}$ concluded that $\mathrm{PE}$ is very common, with an approximate prevalence of $30 \%$ worldwide throughout all age-groups. ${ }^{31}$ Montorsi emphasized the difficulties in determining PE, especially in MSM, where the diagnosis cannot be based upon intravaginal ejaculatory latency. ${ }^{31}$ Although our definition of PE, using invalidated cutoff points of the IPE, is arbitrary, we do believe that our results regarding associated factors of $\mathrm{PE}$ are valuable. We found a significant association between lower level of education and PE, which was contradicted by the results from other studies. ${ }^{34,35}$ All these studies were done in specific subject groups. This makes it even harder for us to draw solid conclusions.

\section{Anodyspareunia}

We think AD gets far too little attention. When we performed a search for anodyspareunia on the PubMed database, only three articles were shown (January 28, 2013) and no Medical
Subject Heading (MeSH) term for anodyspareunia exists. For dyspareunia, a MeSH term exists, but only five papers refer to this term. One recent study of $404 \mathrm{MSM}$ found a prevalence of $14 \% .{ }^{18}$ This is in line with our findings. Furthermore, they concluded that the pain perceived during insertional anal sex is primarily based upon psychological factors ( $57 \%$ ), followed by penis size (40\%), and not enough finger-anus foreplay (26\%). They did not find any significant difference between $\mathrm{HIV}^{-}$and $\mathrm{HIV}^{+}$MSM. They also found a significant relation between the use of poppers and $\mathrm{AD}$, which was not confirmed in our study. In the non-HIV ${ }^{+}$population of the GAMESSS survey, one-third did not practice anal intercourse, and 59\% indicated having some degree of $\mathrm{AD}$, varying from $33 \%$ having a mild form to $2 \%$ suffering from severe AD. The only independent predictor for AD in our study was a more active sex role. This can be explained by the finding of Damon et al that $49 \%$ of men with AD coped with it by restricting their behavior to an active sex role. ${ }^{18}$

\section{Hypoactive sexual desire disorder}

In our study, a higher frequency of masturbation and lower lifetime number of sexual partners were associated with HSDD. Knowing being $\mathrm{HIV}^{+}$may lead to avoidance of sexual intercourse with a partner and limitation to masturbation only. This may support the findings of a small study in which men with HSDD were found to masturbate significantly more often than the control groups. ${ }^{36}$ The $15 \%$ prevalence of HSDD does not show any difference from the prevalence

Table 5 Logistic regression for PE in a group of 72 Belgian HIV+ MSM

\begin{tabular}{|c|c|c|c|c|c|c|}
\hline & \multicolumn{3}{|c|}{ Bivariate analysis $(95 \% \mathrm{Cl})$} & \multicolumn{3}{|c|}{ Multivariate analysis* $(95 \% \mathrm{CI})$} \\
\hline & Odds ratio & $95 \% \mathrm{Cl}$ & $\boldsymbol{P}$ & Odds ratio & $95 \% \mathrm{Cl}$ & $\mathbf{P}$ \\
\hline \multicolumn{7}{|c|}{ Comparison of subjects with or without PE (IPE $\leq 33)$} \\
\hline Higher level of education & 0.58 & $0.35-0.99$ & 0.05 & 0.4 & $0.20-0.81$ & 0.01 \\
\hline Sum of lifetime sex partners & 0.51 & $0.29-0.91$ & 0.02 & 0.32 & $0.15-0.68$ & $<0.001$ \\
\hline No steady relationship & 2.69 & $0.78-9.26$ & 0.12 & 5.42 & $1.17-25.18$ & 0.03 \\
\hline
\end{tabular}

Note: *In the multivariate analysis, both forward and backward stepwise logistic regression analysis was performed, with identical results.

Abbreviations: PE, premature ejaculation; MSM, men who have sex with men; IPE, Index of Premature Ejaculation; $\mathrm{Cl}$, confidence interval. 
in the general male population, reported to be $15 \% .{ }^{19}$ This can be surprising, as it has been reported that in $89 \%$ of men, decrease or loss of libido is seen after beginning HIV treatment. ${ }^{7}$ Yet our study does not include any information regarding HIV treatment. In previous reports, an association was seen between age and sexual problems. ${ }^{20,37}$ None of our multivariate models could confirm this.

\section{Erectile enhancement products}

This study gave also an interesting view on the sexual behaviors of Belgian $\mathrm{HIV}^{+}$MSM. One-third reported using an EEP in the last 4 weeks. The majority used the illegal drug Kamagra. Fisher et al showed associations between being MSM, the knowledge of $\mathrm{HIV}^{+}$status, and the use of sildenafil citrate. ${ }^{38}$ This may be confirmed by the findings of Schnetzler et al. They showed that only $11 \%$ of the general male population reported phosphodiesterase type 5 inhibitor (PDE5i) intake in the last 6 months, with a proportion of $32 \%$ getting this without having a prescription. ${ }^{39}$ They also showed that being embarrassed to talk to a physician was a strong predictive factor for doing so. If these results could be extrapolated to $\mathrm{HIV}^{+} \mathrm{MSM}$, we think that there is still a long way to go for physicians in actively addressing these problems with their patients and offering evidence-based treatment. Fisher et al pointed out the place PDE5i is taking in the world of recreational drugs and the accompanying sexual risks that go with it. ${ }^{38}$ Men who received their ED drugs without prescription reported having more risky sexual behavior. ${ }^{40,41}$

\section{Study limitations}

The study population was limited to 72 participants. This sample can probably not be generalized. Our study group had a high amount of sexual partners. Two out of three stated that they had had more than 100 sexual partners. This surpasses the findings of Shindel et al, who reported that $25 \%$ of their MSM had more than 100 sexual partners. ${ }^{20}$ Furthermore, $83 \%$ of our participants had had more than three sexual partners at the same time.

With the Internet-based survey having been drawn up in 2008, some of the instruments used are now dated. This is partly true for the IIEF-5, which could now be replaced by an MSM- and $\mathrm{HIV}^{+}$-specific tool developed by Coyne et al in $2010 .{ }^{42}$ For the evaluation of PE, nowadays we would choose the PEDT, which is more widely used and has validated cutoff points. ${ }^{43}$ DeRogatis et al showed that a brief structured interview, done by a clinician, is an appropriate way to identify men with HSDD. ${ }^{44}$ In diagnosing AD, still no widely used validated tools are at hand. For their research on AD, Damon and Rosser used two different sets of criteria to assess AD: clinical criteria based upon Diagnostic and Statistical Manual of Mental Disorders, 4th edition criteria for female dyspareunia and behavioral criteria consisting of two Likert scales. ${ }^{18}$

Because older people have less access to and usage of the Internet, older MSM are likely to be underrepresented. A great benefit of e-research is that the interview happens anonymously, so respondents will be more likely to answer in all openness to more sensitive questions. Not knowing who is actually responding may be a weakness in our survey.

\section{Conclusion}

This is the first published study focusing on SD in Belgian $\mathrm{HIV}^{+} \mathrm{MSM}$. We saw a $56 \%$ prevalence of ED, making it the most prevalent $\mathrm{SD}$ among $\mathrm{HIV}^{+} \mathrm{MSM}$. For every SD included in this survey, we found at least one independent predictor. A worrisome percentage of $24 \%$ were using illegal PDE5is without prescription. We hope that this study can encourage other researchers in their exploration of the world of SDs in $\mathrm{HIV}^{+} \mathrm{MSM}$.

\section{Acknowledgments}

The authors thank all participating men for the registration. The study protocol was approved by the ethical committee of the university hospital of the Vrije Universiteit Brussel. The study was not funded by an external organization. The condoms for the promotion of the study were provided by LSE Holland.

\section{Disclosure}

Johan Vansintejan reports that he serves as a consultant to Boehringer Ingelheim, Menarini Belgium, and Eli Lilly. He has no stock or ownership to report. None of the other authors has a conflict of interest, including ownership of shares, consultancy, speaker's honoraria, or research grants from commercial companies or professional or governmental organizations with an interest in the topic of the paper.

\section{References}

1. Gallo RC. A reflection on HIV/AIDS research after 25 years. Retrovirology. 2006;3:72.

2. De Cock KM, Jaffe HW, Curran JW. The evolving epidemiology of HIV/ AIDS. AIDS. 2012;26:1205-1213.

3. Sasse A, Verbrugge R, Van Beckhoven D. Epidemiology of AIDS and HIV infection in Belgium. Brussels: Volksgezondheid and Surveillance; 2011. Dutch.

4. Lau JT, Kim JH, Tsui HY. Prevalence and sociocultural predictors of sexual dysfunction among Chinese men who have sex with men in Hong Kong. J Sex Med. 2008;5:2766-2779. 
5. Cove J, Petrak J. Factors associated with sexual problems in HIVpositive gay men. Int J STD AIDS. 2004;15:732-736.

6. Mao 1, Newman CE, Kidd MR, Saltman DC, Rogers GD, Kippax SC. Self-reported sexual difficulties and their association with depression and other factors among gay men attending high HIV-caseload general practices in Australia. $J$ Sex Med. 2009;6:1378-1385.

7. Lallemand F, Salhi Y, Linard F, Giami A, Rozenbaum W. Sexual dysfunction in 156 ambulatory HIV-infected men receiving highly active antiretroviral therapy combinations with and without protease inhibitors. J Acquir Immune Defic Syndr. 2002;30:187-190.

8. Chalmers A, Catalan J, Nelson M, Day A. Sexual dysfunction in HIV seropositive gay men. Int Conf AIDS. 1992;8:65.

9. Hirshfield S, Chiasson MA, Wagmiller RL Jr, et al. Sexual dysfunction in an Internet sample of US men who have sex with men. J Sex Med. 2010;7:3104-3114.

10. Lamba H, Goldmeier D, Mackie NE, Scullard G. Antiretroviral therapy is associated with sexual dysfunction and with increased serum oestradiol levels in men. Int J STD AIDS. 2004;15:234-237.

11. Tindall B, Forde S, Goldstein D, Ross MW, Cooper DA. Sexual dysfunction in advanced HIV disease. AIDS Care. 1994;6: 105-107.

12. Bancroft J, Carnes L, Janssen E. Unprotected anal intercourse in HIVpositive and HIV-negative gay men: the relevance of sexual arousability, mood, sensation seeking, and erectile problems. Arch Sex Behav. 2005;34:299-305.

13. The Data Collection on Adverse Events of Anti-HIV drugs (D:A:D) Study Group, Smith C, Sabin CA, et al. Factors associated with specific causes of death amongst HIV-positive individuals in the D:A:D study AIDS. 2010;24:1537-1548.

14. Lewden C, Chene G, Morlat P, Raffi F, Dabis F, Leport C. [Mortality rate of HIV-infected adults compared with the general population: long-term and CD4-lymphocyte-dependent results]. Med Sci (Paris). 2008;24:804-806. French.

15. Mykletun A, Dahl AA, O'Leary MP, Fosså SD. Assessment of male sexual function by the Brief Sexual Function Inventory. BJU Int. 2006;97:316-323.

16. Platteau T, van Lankveld J. [Sexual dysfunction in gay men with HIV: a literature review]. Tijdschrift Voor Seksuologie. 2005;29:205-214 Dutch.

17. Mak R, De Berardis G, Kornitzer M, De Meyer JM. Prevalence and correlates of erectile dysfunction in a population-based study in Belgium. Eur Urol. 2002;41:132-138.

18. Damon W, Rosser BR. Anodyspareunia in men who have sex with men: prevalence, predictors, consequences and the development of DSM diagnostic criteria. J Sex Marital Ther. 2005;31:129-141.

19. Rosen RC. Prevalence and risk factors of sexual dysfunction in men and women. Curr Psychiatry Rep. 2000;2:189-195.

20. Shindel AW, Vittinghof E, Breyer BN. Erectile dysfunction and premature ejaculation in men who have sex with men. J Sex Med. 2012;9: 576-584.

21. McMahon CG, Lee G, Park JK, Adaikan PG. Premature ejaculation and erectile dysfunction prevalence and attitudes in the Asia-Pacific region. J Sex Med. 2012;9:454-465.

22. Vansintejan J, Vandevoorde J, Devroey D. The Gay Men Sex Studies: design of an online registration of sexual behaviour of men having sex with men and preliminary results (GAMESSS-study). Cent Eur J Public Health. 2013;21:239-243.

23. Kinsey AC, Pomeroy WR, Martin CE. Sexual behavior in the human male. 1948. Am J Public Health. 2003;93:894-898.

24. Althof S, Rosen R, Symonds T, Mundayat R, May K, Abraham L. Development and validation of a new questionnaire to assess sexual satisfaction, control and distress associated with premature ejaculation. J Sex Med. 2006;3:465-475.

25. Rosen RC, Cappelleri JC, Smith MD, Lipsky J, Pena BM. Development and evaluation of an abridged, 5-item version of the International Index of Erectile Function (IIEF-5) as a diagnostic tool for erectile dysfunction. Int J Impot Res. 1999;11:319-326.
26. Isidori AM, Pozza C, Esposito K, et al. Development and validation of a 6-item version of the Female Sexual Function Index (FSFI) as a diagnostic tool for female sexual dysfunction. J Sex Med. 2010;7: 1139-1146.

27. Gerstenberger EP, Rosen RC, Brewer JV, et al. Sexual desire and the Female Sexual Function Index (FSFI): a sexual desire cutpoint for clinical interpretation of the FSFI in women with and without hypoactive sexual desire disorder. $J$ Sex Med. 2010;7:3096-3103.

28. Ferguson GG, Nelson CJ, Brandes SB, Shindel AW. The sexual lives of residents and fellows in graduate medical education programs: a single institution survey. J Sex Med. 2008;5:2756-2765.

29. Fugl-Meyer KS, Lewis RW, Corona G, et al. Definitions, classification and epidemiology of sexual dysfunction. In: Montorsi F, Basson R, Adaikan G, et al, editors. Sexual Medicine: Sexual Dysfunctions in Men and Women. Bristol: ICUD; 2010:46-47.

30. Brotto LA. The DSM diagnostic criteria for hypoactive sexual desire disorder in men. $J$ Sex Med. 2010;7:2015-2030.

31. Montorsi F. Prevalence of premature ejaculation: a global and regional perspective. J Sex Med. 2005;2:96-102.

32. Hart TA, Moskowitz D, Cox C, et al. The cumulative effects of medication use, drug use, and smoking on erectile dysfunction among men who have sex with men. $J$ Sex Med. 2012;9:1106-1113.

33. Ende AR, Lo ReV 3rd, DiNubile MJ, Mounzer K. Erectile dysfunction in an urban HIV-positive population. AIDS Patient Care STDS. 2006;20: $75-78$.

34. Tignol J, Martin-Guehl C, Aouizerate B, Grabot D, Auriacombe M. Social phobia and premature ejaculation: a case-control study. Depress Anxiety. 2006;23:153-157.

35. Laumann EO, Nicolosi A, Glasser DB, et al. Sexual problems among women and men aged 40-80 y: prevalence and correlates identified in the Global Study of Sexual Attitudes and Behaviors. Int J Impot Res. 2005;17:39-57.

36. Nutter DE, Condron MK. Sexual fantasy and activity patterns of males with inhibited sexual desire and males with erectile dysfunction versus normal controls. $J$ Sex Marital Ther. 1985;11:91-98.

37. Asboe D, Catalan J, Mandalia S, et al. Sexual dysfunction in HIVpositive men is multi-factorial: a study of prevalence and associated factors. AIDS Care. 2007;19:955-965.

38. Fisher DG, Malow R, Rosenberg R, Reynolds GL, Farell N, Jaffe A. Recreational Viagra use and sexual risk among drug abusing men. $\mathrm{Am}$ J Infect Dis. 2006;2:107-114.

39. Schnetzler G, Banks I, Kirby M, Zou KH, Symonds T. Characteristics, behaviors, and attitudes of men bypassing the healthcare system when obtaining phosphodiesterase type 5 inhibitors. $J$ Sex Med. 2012;7:1237-1246.

40. Marks G, Richardson JL, Milam J, Bolan R, Syoyanoff S, McCutcham A. Use of erectile dysfunction medication and unsafe sex among HIV+ men who have sex with men in care. Int J STD AIDS. 2005;16:271-272.

41. Goltz HH, Coon DW, Catania JA, Latini DM. A pilot study of HIV/ STI risk among men having sex with men using erectile dysfunction medications: challenges and opportunities for sexual medicine physicians. J Sex Med. 2012;9:3189-3197.

42. Coyne K, Mandalia S, McCullough S, et al. The International Index of Erectile Function: development of an adapted tool for use in HIVpositive men who have sex with men. J Sex Med. 2010;7:769-774.

43. Symonds T, Perelman MA, Althof S, et al. Development and validation of a premature ejaculation diagnostic tool. Eur Urol. 2007;52: $565-573$.

44. DeRogatis L, Rosen RC, Goldstein I, Werneburg B, KempthorneRawson J, Sand M. Characterization of hypoactive sexual desire disorder (HSDD) in men. $J$ Sex Med. 2012;9:812-820. 
HIV/AIDS - Research and Palliative Care

\section{Dovepress}

\section{Publish your work in this journal}

HIV/AIDS - Research and Palliative Care is an international, peerreviewed open-access journal focusing on advances in research in HIV, its clinical progression and management options including antiviral treatment, palliative care and public healthcare policies to control viral spread. The journal welcomes original research, basic science,

clinical \& epidemiological studies, reviews \& evaluations, expert opinion \& commentary, case reports \& extended reports. The manuscript management system is completely online and includes a very quick and fair peer-review system. Visit http://www.dovepress.com/ testimonials.php to read real quotes from published authors.

Submit your manuscript here: http://www.dovepress.com/hivaids---research-and-palliative-care-journal 